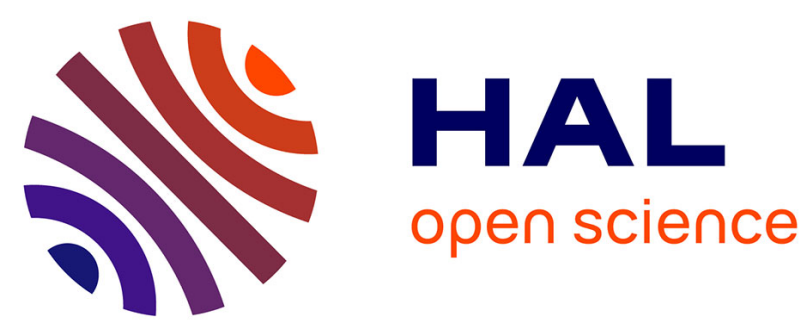

\title{
GravPSO2D: A Matlab package for 2D gravity inversion in sedimentary basins using the Particle Swarm Optimization algorithm
}

\author{
J.L.G. Pallero, J.L. Fernández-Martínez, Z. Fernández-Muñiz, Sylvain \\ Bonvalot, Germinal Gabalda, Thierry Nalpas
}

\section{To cite this version:}

J.L.G. Pallero, J.L. Fernández-Martínez, Z. Fernández-Muñiz, Sylvain Bonvalot, Germinal Gabalda, et al.. GravPSO2D: A Matlab package for 2D gravity inversion in sedimentary basins using the Particle Swarm Optimization algorithm. Computers \& Geosciences, 2021, 146, pp.104653. 10.1016/j.cageo.2020.104653 . insu-02998258

\section{HAL Id: insu-02998258 \\ https://hal-insu.archives-ouvertes.fr/insu-02998258}

Submitted on 10 Nov 2020

HAL is a multi-disciplinary open access archive for the deposit and dissemination of scientific research documents, whether they are published or not. The documents may come from teaching and research institutions in France or abroad, or from public or private research centers.
L'archive ouverte pluridisciplinaire HAL, est destinée au dépôt et à la diffusion de documents scientifiques de niveau recherche, publiés ou non, émanant des établissements d'enseignement et de recherche français ou étrangers, des laboratoires publics ou privés. 


\section{Journal Pre-proof}

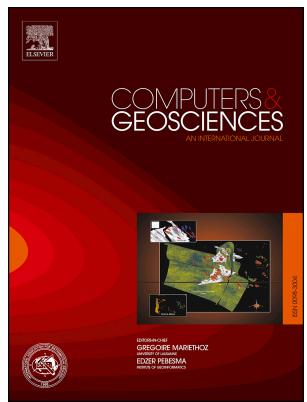

J.L.G. Pallero, J.L. Fernández-Martínez, Z. Fernández-Muñiz, S. Bonvalot, G.

Gabalda, T. Nalpas

GravPSO2D: A Matlab package for 2D gravity inversion in sedimentary basins using the Particle Swarm Optimization algorithm

PII: S0098-3004(20)30629-4

DOI: $\quad$ https://doi.org/10.1016/j.cageo.2020.104653

Reference: CAGEO 104653

To appear in: Computers and Geosciences

Received Date: 17 February 2020

Revised Date: 23 October 2020

Accepted Date: 28 October 2020

Please cite this article as: Pallero, J.L.G., Fernández-Martínez, J.L., Fernández-Muñiz, Z., Bonvalot, S., Gabalda, G., Nalpas, T., GravPSO2D: A Matlab package for 2D gravity inversion in sedimentary basins using the Particle Swarm Optimization algorithm, Computers and Geosciences (2020), doi: https:// doi.org/10.1016/j.cageo.2020.104653.

This is a PDF file of an article that has undergone enhancements after acceptance, such as the addition of a cover page and metadata, and formatting for readability, but it is not yet the definitive version of record. This version will undergo additional copyediting, typesetting and review before it is published in its final form, but we are providing this version to give early visibility of the article. Please note that, during the production process, errors may be discovered which could affect the content, and all legal disclaimers that apply to the journal pertain.

(C) 2020 Published by Elsevier Ltd. 


\title{
GRAvPSO2D: A Matlab package for 2D gravity inversion in sedimentary basins using the Particle Swarm Optimization algorithm
}

\author{
J.L.G. Pallero ${ }^{\mathrm{a}, *}$, J.L. Fernández-Martínez ${ }^{\mathrm{b}}$, Z. Fernández-Muñiz ${ }^{\mathrm{b}}$, S. Bonvalot ${ }^{\mathrm{c}}$, \\ G. Gabalda ${ }^{\mathrm{c}}$, T. Nalpas ${ }^{\mathrm{d}}$ \\ ${ }^{a}$ ETSI en Topografía, Geodesia y Cartografía. Universidad Politécnica de Madrid. Madrid, \\ Spain \\ ${ }^{b}$ Grupo de Problemas Inversos, Optimización y Aprendizaje Automático. Departamento de \\ Matemáticas. Universidad de Oviedo, Oviedo, Spain \\ ${ }^{c}$ GET (Université de Toulouse, CNRS, IRD, CNES) - Bureau Gravimétrique International (BGI), \\ Toulouse, France \\ ${ }^{d}$ Univ Rennes, CNRS, Géosciences Rennes, UMR 6118, 35000 Rennes, France
}

\begin{abstract}
In this paper GRAvPSO2D, a Matlab tool for two-dimensional gravity inversion in sedimentary basins using the Particle Swarm Optimization (PSO) algorithm, is presented. The package consists of a collection of functions and scripts that cover the main three parts of the process: (1) the model definition based on the observations, (2) the inversion itself, where the PSO is employed, and (3) the results processing, including best model estimation, uncertainty analysis and plots generation. GRAVPSO2D is freely available, and represents an effort for providing

${ }^{*}$ Corresponding author

Email addresses: jlg.pallero@upm.es (J.L.G. Pallero), jlfm@uniovi.es (J.L.

Fernández-Martínez), zulima@uniovi .es (Z. Fernández-Muñiz),

sylvain.bonvalot@ird.fr (S. Bonvalot), germinal.gabalda@ird.fr (G. Gabalda),

thierry.nalpas@univ-rennes1.fr (T. Nalpas)

Author contributions: J.L.G.P., J.L.F.M., and Z.F.M. designed the methodology, developed the software, processed the data, and wrote the paper. G.G., and T.N. acquired the gravity data. S.B., G.G., and T.N. analyzed, discussed the inversion results corresponding to the real example, and wrote the related part of the paper.
\end{abstract}


the scientific community with the first tool based on the PSO algorithm in order perform the inversion and the uncertainty assessment of the sedimentary basin gravity inversion problem, taking into account the gravity regional trend estimation, and vertically and horizontally density contrast variations. Synthetic and real examples are provided in order to show the software capabilities.

Keywords: Nonlinear gravity inversion, Particle Swarm Optimization, Uncertainty assessment, Sedimentary basin

\section{Introduction}

The interface separation between two media having different densities can be estimated in Geophysics using gravity measurements and by posing a nonlinear inverse problem. Gravity inversion in this kind of environments is a tool frequently used in Geophysics in tasks such as prospecting of oil and gas, or in hydrogeology and glaciology studies (Blakely, 1995; Dobrin, 1960; Hinze et al., 2013; Nettleton, 1976; Parker, 1994; Telford et al., 1976). The gravity inverse problem has a non-unique solution, leading to an infinity number of solutions (Al-Chalabi, 1971; Skeels, 1947; Zhdanov, 2015). It is therefore mandatory to introduce some kind of regularization and/or constraint(s) incorporating other geophysical information such as borehole and seismic profile data, contrasted prior models, etc. This will allow to restrict the set of possible solutions and stabilize the inversion.

The problem of the estimation of the basement relief in sedimentary basins using gravity observations is a nonlinear inverse problem, and the most used techniques for its solution are based on local optimization methods, either by the linearization of the problem plus regularization (see Silva et al. (2009) for example), or by the sequential application of the direct formulation (see Bott (1960) or Chen 
and Zhang (2015) for example). GravPSO2D uses Particle Swarm Optimization (PSO), which is a global search method with excellent capabilities to perform the inverse problem uncertainty analysis and avoiding the weak points of the local optimization procedures, such as the dependency on the prior model and the lack of a proper uncertainty analysis (Fernández-Martínez et al., 2013, 2014b).

GravPSO2D works in two-dimensional environments. This approximation can be used when the dimension of an anomalous body is much larger than the other two dimensions (at least a $4 \times$ or $6 \times$ factor according to Nettleton (1976)). This situation is common in sedimentary basins, where their horizontal extensions are generally much larger than their depth, so profiles perpendicular to the principal dimensions can be used for the analysis in a 2D formulation (Pick et al., 1973; Telford et al., 1976).

\section{Observations and basin modelization}

GRAvPSO2D works with user-provided complete Bouguer gravity anomalies, $\Delta \mathrm{g}$, along a profile. The software can also estimate a polynomial regional trend during the inversion, so if this effect exists in $\Delta \mathrm{g}$ it is not necessary to be previously suppressed by the user.

The 2D basin modeling used in GravPSO2D consists in the juxtaposition of rectangles along the profile as it was commonly employed by other authors (see for example Silva et al. (2009) or Ekinci et al. (2020)). As it can be seen in Fig. B.1, the rectangles' upper sides are located at the surface level (considered plane in the figure, although that is not mandatory, so they can be adapted to the terrain topography). It is common to set the horizontal dimensions to be equal for all rectangles, but GRAvPSO2D can also work with unequal widths. Then, the 
bottom sides depict the sediments-basement interface.

\section{FIGURE B.1 HERE (ONE COLUMN WIDTH)}

Let $N$ be the number of observed gravity points, $P_{i}\left(l_{i}, z_{i}\right)$, with $i=1 \ldots N$, and where $l_{i}$ is the point position along the profile length, and $z_{i}$ the point height. The gravity residual anomaly generated over each point by a model composed of $M$ rectangles follows the equation

$$
\Delta \mathrm{g}_{P_{i}}^{\mathrm{r}}=\sum_{j=1}^{M} F\left(\Delta \rho\left(z_{j}\right), z_{j}, \mathbf{r}_{i j}\right),
$$

where $F$ is the forward operator (see Appendix A), $\Delta \rho\left(z_{j}\right)$ is the particular rectangle density contrast, constant or variable with depth, $z_{j}$ is the particular rectangle bottom side height (the problem unknowns), and $\mathbf{r}_{i j}$ is the position vector of each rectangle related to each observation point. If a polynomial regional trend is added, which contributes with the anomaly $\Delta \mathrm{g}^{\mathrm{t}}$, the gravity anomaly over each observation point is:

$$
\begin{aligned}
\Delta \mathrm{g}_{P_{i}} & =\Delta \mathrm{g}_{P_{i}}^{\mathrm{r}}+\Delta \mathrm{g}_{P_{i}}^{\mathrm{t}} \\
& =\sum_{j=1}^{M}\left[F\left(\Delta \rho\left(z_{j}\right), z_{j}, \mathbf{r}_{i j}\right)+\sum_{k=D}^{0} A_{k}\left(l_{i}-l_{r}\right)^{k}\right],
\end{aligned}
$$

where $D$ is the polynomial degree, $A_{k}$ are the polynomial coefficients, and $l_{r}$ is a reference position.

In real environments sediments' density typically increases with depth, so the density contrast sediments-basement, $\Delta \rho$, decreases. GRavPSO2D can work with both, constant or variable density contrast. In the latter case, this variation can be vertical (with depth), and also horizontal.

Many models of density contrast variation with depth have been used in the literature. Constant values are frequently used (Barbosa et al., 1997, 1999), but vari- 
able density contrast is also very common: Rao (1990) used a quadratic equation, Chakravarthi and Sundararajan (2007) a parabolic law, Litinsky (1989); Silva et al. (2006) a hyperbolic law, and Parker (1972); Granser (1987); Pham et al. (2018) an exponential law. All these models produce complicated equations hard to manage that do not match well the density variation with depth in some real environments (see for example density logs in Brocher (2005) or Silva et al. (2006)).

In order to manage the vertical density contrast variation, GRAvPSO2D can use a piecewise model, having the advantages of (1) any density variation can be used, and (2) only the formulation corresponding to the constant density model (Eq. (A.1)) is needed. An example can be seen in Fig. B.2, where a constant value of $\Delta \rho=-600 \mathrm{~kg} \mathrm{~m}^{-3}$ is used between depths from $0 \mathrm{~m}$ to $100 \mathrm{~m}$; then, a linear variation from $\Delta \rho=-570 \mathrm{~kg} \mathrm{~m}^{-3}$ to $\Delta \rho=-520 \mathrm{~kg} \mathrm{~m}^{-3}$ is used between depths $100 \mathrm{~m}$ to $150 \mathrm{~m}$, and finally a constant value of $\Delta \rho=-520 \mathrm{~kg} \mathrm{~m}^{-3}$ is employed for depths greater than $150 \mathrm{~m}$. GravPSO2D divides each subsoil model's rectangle based on the density profile for computing the whole attraction, and uses constant density sub-rectangles of user-defined size to approximate the zones with density variation.

\section{FIGURE B.2 HERE (ONE COLUMN WIDTH)}

GravPSO2D can also manage horizontal density contrast distributions. In this case the gravity profile is divided into horizontal sectors, and different vertical density contrast models are assigned to each one. All these configurations are provided via text files. 


\section{Particle Swarm Optimization}

The PSO (Particle Swarm Optimization) algorithm (Kennedy and Eberhart, $1995)$ is a global optimizer based on the the behavior of swarms of animals (birds, fish schools) in the nature searching for food. A set of particles (models) explores the parameters' space with the goal of the optimization of a given cost function related to the inverse problem that is considered. As general overview, the algorithm works as follows: (1) in the first step, a set of particles (models) is created with random positions (the problem parameters) and velocities, and the objective function is employed to determine the fitness of each model in the set, (2) as time passes, the particles' position and velocity are updated based on their fitness and the corresponding values of their neighbors, i. e., the behavior of an individual is influenced by its own experience and that of its neighbors (Fernández-Martínez et al., 2008).

The algorithm depends internally of a set of parameters, where the more important are the so-called inertia weight, and local and global accelerations. Modifying how the velocities and accelerations of the particles are described a family of PSO variants are describle, and among them GravPSO2D can use the so-called GPSO, CC-PSO, CP-PSO, PC-PSO, PP-PSO, PR-PSO, RC-PSO, RP-PSO and RR-PSO family members (Fernández-Martínez and García-Gonzalo, 2009, 2012; García-Gonzalo et al., 2014). The cloud versions of these algorithms are used, i. e., no parameter tuning of inertia nor accelerations must be configured by the user, given that each the particle has its own PSO parameters, automatically chosen (García-Gonzalo and Fernández-Martínez, 2009).

Pioneer applications of PSO in the field of applied geophysics can be seen in Fernández-Álvarez et al. (2006); Fernández-Martínez et al. (2010a,b); Shaw and 
Srivastava (2007). In Fernández-Martínez et al. (2010a), for example, an application of PSO to a 1D-DC resistivity inverse problem is presented. More recently, in Luu et al. (2018) an application to the seismic traveltime tomography problem can be seen, and in Li et al. (2019) PSO is applied to microseismic location. Nevertheless, in gravity and other potential field inversion methods the PSO algorithm has been barely used (Essa and Elhussein (2018), for example, apply PSO in the inversion of magnetic anomalies generated by simple structures).

In Sanyi et al. (2009) several simple gravity synthetic examples based on buried cyclinders are solved using PSO, comparing the obtained results with other global search methods (genetic algorithms, simulated annealing, and ant colony optimization), and also with a classical Levenberg-Marquardt approach. In Toushmalani (2013a,b) PSO was employed to estimate the parameters of a fault based on gravity anomaly observations. The conclusion of the study is that PSO provides better agreement between the estimated and the synthetic model anomaly than the classical approach using linearization and the Levenberg-Marquardt method. In Roshan and Singh (2017) PSO is employed in the gravity inversion of a spherical and a vertical cylindrical models, as well as its application to a real example (modeled as a vertical cylinder). In all these papers PSO is employed as a global optimizer, and performance tests are performed in most cases against local optimization techniques. But the most important feature of global optimization algorithms is missed: their capability to perform an approximate nonlinear uncertainty analysis of the inverse solution by the sampling of the nonlinear uncertainty region(s). Few papers were found (Singh and Biswas, 2016; Ladino and Bassrei, 2016) where the inversion uncertainty is analyzed using the frequency distribution of the model parameters and/or cross-plots of parameters. In Fernández-Muñiz 
et al. (2020) an application of PSO to gravity inversion of isolated anomalous bodies plus uncertainty assessment using PSO can also be seen.

In Pallero et al. (2015, 2017), a first attempts to apply the PSO algorithm to the gravity inverse problem in sedimentary basins were presented for $2 \mathrm{D}$ and 3D environments, respectively. In Ladino and Bassrei (2016) a mixed model of PSO plus regularized Gauss-Newton method is employed for 3D gravity inverse problem in sedimentary basins, where PSO provides the initial model for a final GaussNewton inversion and cross-plots are employed for uncertainty analysis. In Singh and Singh (2017) PSO is applied to a 2.5D gravity inversion in sedimentary basins, although in this case only comparisons with results obtained via the Marquardt method are performed. Finally, Ekinci et al. (2020) have recently used a different global optimization method, called differential evolution algorithm (DEA), to a 2D approximation of this kind of problem applied to the Aegean Graben System (Turkey), performing algo uncertainty analysis.

\section{The 2D basement relief gravity inverse problem and PSO}

In this section a general overview about the 2D basement relief gravity inverse problem in the frame of the PSO algorithm is presented. The main configuration parameters and other details are enumerated and explained.

The first important parameters to impose for the PSO execution are the search space limits, which are established based on a first approximation model estimated using the Bouguer's plate formulation. It is important to stress that this first approximation model does not act as the initial model in the local optimization methods, but it is only a guidance for the PSO search bounds determination, therefore not much accuracy is needed (this topic is explained in detail in the 
GravPSO2D reference manual). Then, other important parameters to select are the swarm size and the number of iterations. At each iteration, a number of models equal to the swarm size are generated, i. e., the search space is sampled during the PSO execution. After each iteration the cost function value for each model is computed, which is a value that has influence in the posterior swarm evolution. This cost function is defined as

$$
c=\frac{\|\mathbf{v}\|_{p}}{\|\mathbf{o}\|_{p}} \cdot 100,
$$

where $p$ is a user-selected vector norm. In the last step of the algorithm all generated models are analyzed according to their cost function values.

The vector $\mathbf{o}$ is defined as

$$
\mathbf{o}=\Delta \mathbf{g}^{\mathrm{o}}-\Delta \mathbf{g}^{\mathrm{t}},
$$

i. e., the vector of observed gravity anomaly minus the regional trend values (if they are estimated during the inversion or imposed). The vector $\mathbf{v}$ is defined as

$$
\mathbf{v}=\Delta \mathbf{g}^{\mathrm{o}}-\Delta \mathbf{g}^{\mathrm{t}}-\Delta \mathbf{g}^{\mathrm{r}},
$$

i. e., the vector of observed gravity anomaly minus the regional trend values (if they are estimated during the inversion or imposed) minus the residual gravity generated by the corresponding subsoil model in the swarm. If the observations have an associated standard deviation information, it can be used in GravPSO2D for weighting the cost function computation.

Other important aspect in GravPSO2D is model filtering. The direct application of global search algorithms to the sedimentary basin gravity inverse problem produces unrealistic models characterized by a sawtooth profile (Boschetti et al., 
1997; Parker, 1999; Pallero et al., 2015). This can be mitigated via a moving average filtering applied to the generated PSO models, and prior to the computation of the pertinent cost function value. Filtering is in this case the way to introduce relative constraints (Barbosa et al., 1997) in the problem, and the use of average filtering technique permits a flexible configuration of the method behavior for different values in the filtering window.

Finally, using absolute constraints (Barbosa et al., 1997) is also possible. Absolute constraints are values of sediments-basement interface depths (or minimum depths) that can come from boreholes, seismic profiles or other sources. These data can be used to fix (or permit a small variation around a value) the depth value of parts of the subsoil model and its surroundings.

\section{The GravPSO2D package}

The GravPSO2D package is a Matlab software, so it is possible to work with it in any operating system where Matlab ${ }^{1}$ is present.

\subsection{Package organization and installation}

Once the user has downloaded and uncompressed the package, a folder called grav-pso-2d/ will be obtained. This folder contains the following elements:

- A folder called pso_programs_v3/ containing the Particle Swarm Optimization code.

${ }^{1}$ Matlab 9.2.0.538062 (R2017a) Linux version (under Debian GNU Linux) was employed in the writing of the software, but, as no special packages nor extensions are used, any version should be capable to execute GravPSO2D. 
- A folder called doc/ that stores a complete and self-contained 61-page reference manual.

- A folder called examples/ containing the example data.

- A collection of 14 files whose names follow the template grav2d_*.m.

\subsection{Main scripts}

On the user side, GravPSO2D is composed by three main scripts, which are:

- grav2d_ModelDefinition.m. This script helps to prepare the data prior to the inversion. Based on the observations data file and several user configuration variables, this script performs the subsoil partition.

- grav2d_Inversion.m. This script performs the inversion using the PSO algorithm. The user can select several parameters, such as the PSO family member, the swarm size and the number of iterations, the activation of weights, the vector norm for the cost function evaluation, and others. As a result, the script generates a file containing, among other internal information, all the sampled models, which will be the data to use in the post processing stage.

- grav2d_Plot.m. This script analyzes the results obtained by grav2d_Inversion.m, providing the inversion results in text and graphical modes, which can be configured by the user through some variables.

\subsection{Input data files}

In this section, the different input data files will be enumerated (a detailed description of the different formats is stated in the user's manual). All input data 
files used by GravPSO2D are ASCII files, so it can be opened and edited by any text editor.

- Observations data file. The observations data file contains a gravity profile in rectangular coordinates, and is the fundamental file in GRAVPSO2D.

- Subsoil data file. This file describes the subsoil partition in rectangles, which is the model used by the software, as it was described in section 2 .

- Regional trend data file. If the user wants to use a regional trend in inversion (estimation or only using a predefined one), a first approximation must be introduced via a configuration file. This first approximation does not act as initial approximation as in local optimization algorithms, but only as a reference to compute the search space for the polynomial coefficients in the PSO algorithm.

- Density contrast definition data files. Two files can be configured related to this topic, one for the vertical, and one for the horizontal density contrast variations. In the former case, the vertical variation is configured piecewise providing information about depths and the corresponding density contrast. Multiple configurations can be defined, each one marked by an identifier. In the case of the horizontal density distribution the corresponding file stores a set of segments, and a vertical contrast density configuration is assigned to each of them via the identifier.

- Filtering data file. For the filtering step the user must provide the window filter coefficients, which are stored in a file and can be freely selected. 
- Boreholes data file. In this file borehole information is stored. The user can configure a fixed value or an influence area for a prescribed basement depth.

\subsection{Output files}

The grav2d_Inversion.m script generates after its execution a unique file, stored as Matlab *.mat format (version 7), containing the inversion's results. It contains a structure comprising all the generated models during the PSO execution, as well as all the inversion details (an in-depth description of the structure is presented in the GRAvPSO2D reference manual). This file is loaded by the grav2d_Plot.m in order to generate its results.

\section{Synthetic example}

In this section a synthetic example is presented in order to illustrate the behavior of the GRAVPSO2D software. A synthetic subsoil composed by 126 rectangles of $200 \mathrm{~m}$ horizontal width with upper sides from height $976 \mathrm{~m}$ to $1439 \mathrm{~m}$, and depths are comprised between $10 \mathrm{~m}$ and $513 \mathrm{~m}$ has been created. The density contrast $\Delta \rho$ is variable with depth and also horizontally: two sectors dividing the profile at the middle, the first one with $\Delta \rho=-580 \mathrm{~kg} \mathrm{~m}^{-3}$ between depths from $0 \mathrm{~m}$ to $100 \mathrm{~m}$, and $\Delta \rho=-540 \mathrm{~kg} \mathrm{~m}^{-3}$ for depths greater than $150 \mathrm{~m}$ ( $\Delta \rho$ varies linearly between $100 \mathrm{~m}$, and $150 \mathrm{~m}$ ), and the second one with $\Delta \rho=-600 \mathrm{~kg} \mathrm{~m}^{-3}$ between depths from $0 \mathrm{~m}$ to $110 \mathrm{~m}$, and $\Delta \rho=-570 \mathrm{~kg} \mathrm{~m}^{-3}$ for depths greater than $150 \mathrm{~m}$ ( $\Delta \rho$ varies linearly between $110 \mathrm{~m}$, and $150 \mathrm{~m}$ ). Then a set of 99 points near uniformly distributed, and whose heights coincide with the rectangles top sides were generated. For this points the gravity anomaly corresponding to the subsoil model was generated, and then contaminated with white noise distributed 
as $N(0,0.25) \mathrm{mGal}$. Finally, a linear regional anomaly was added to each point following the trend

$$
\Delta \mathrm{g}^{\mathrm{t}}=A_{1}\left(l-l_{r}\right)+A_{0},
$$

where $A_{1}=1.2 \cdot 10^{-3} \mathrm{mGal} \mathrm{m}^{-1}, A_{0}=-99.042 \mathrm{mGal}, l_{r}=10798.699 \mathrm{~m}$, and $l$ is the position in the profile of each point.

The previous configuration was employed, as it was explained, for the gravity signal generation. But for the inversion a reduced model was used in order to mimic a real situation, i. e., in a real application the subsoil model is always an idealized and simplified version of a real environment. First of all, the subsoil model in the reduced version is composed by 51 rectangles of $500 \mathrm{~m}$ horizontal width, while the vertical and horizontal density contrast variations are the same as in the original model. The number of observation points used in the inversion is in this case 39, which were randomly selected from the original set of 99 points. Finally, the linear regional trend model will be estimated during the inversion.

For the inversion, the CP-PSO family member was selected, and three repetitions of the algorithm were combined using in each one a swarm of 200 models, and performing in each case 100 iterations, i. e., a total of 60000 models were generated. The user is strongly encouraged to read the GRAvPSO2D reference manual in order to obtain an extended discussion about the behavior of the different PSO family members and about the different approaches to perform an inversion.

For the filtering step, a window of width 5 elements was selected, being all the coefficients of value 1. Two passes of the filter were employed, because it was observed that in order to obtain smooth results (and in this synthetic example this is the kind of the sediments-basement interface) it is more convenient to use a narrow window combined with two passes instead of a single pass with a 
wider filtering window. Also borehole information as absolute constraints were used, considering semi fixed (with a $10 \mathrm{~m}$ freedom) the depths of three rectangles (numbers 12,13, and 31). About the cost function computation, the $L_{2}$ norm is employed considering weights based on the inverse of the observations variances.

\section{FIGURE B.3 HERE (TWO COLUMN WIDTH)}

Fig. B.3 (left) shows the general results of the inversion corresponding to the best model (the one among all the generated models which produces the minimum cost function value, which corresponds to a $2.91 \%$ relative misfit). This plot is generated by the grav2d_Plot.m script, and it is composed mainly by two parts. The upper one shows the inversion residuals corresponding to each observation point, while the lower part presents a general overview of the estimated sediments-basement interface. This interface is composed, in turn, by the depths corresponding to the best model, and a range of depths comprising all generated models inside the equivalent region with relative misfit lower than a selected value by the user, $4.5 \%$, in this case. At this point there is a limitation related to the filtering step that must be taken into account. Due to border effects in filtering the rectangles close to the profile ends must be analyzed carefully, and sometimes ignored. In such rectangles, where in general the sediments depth is shallow, the border effects of the filtering step produce in many cases unrealistic results that could not match the actual basement-sediments interface.

Fig. B.4 presents an important plot also generated by the grav2d_Plot.m script. For each rectangle, this plot contains in its upper part the cumulative distribution function computed using all the models inside the working equivalent region ( $4.5 \%$ in this example), and in its lower part the corresponding histogram. These plots are important because the user can inspect the probability distribution 
of each parameter in detail. In this case, the distribution for the rectangle number 22 is clearly unimodal with depth $491.3 \mathrm{~m}$, and quasi-symmetrical. This is a more convenient way to describe the uncertainty in nonlinear inverse problems than its classical expression through the most probable value plus a standard deviation, specially when the probability is far from the normal distribution (Pallero et al., 2018). But in B.4 it can also be seen that the most probable depth according to the histogram for rectangle number $22(491.3 \mathrm{~m})$ does not match the depth deduced from the best model $(497.5 \mathrm{~m})$, i. e., the global best model (the one with the lowest relative misfit) is not necessary composed by the set of the most probable depths of each individual rectangle. In this particular case, the relative difference in depths with respect to the depth from the best model is $1.25 \%$.

FIGURE B.4 HERE (ONE COLUMN WIDTH)

In addition to the best model, a model composed by the individual most probable depths of each rectangle is generated by grav2d_Plot.m and called median model. In this example, the median model has a relative misfit of $3.33 \%$ (see Fig. B.3, right), and together with the best model and the individual histograms provides a powerful information to perform the inverse problem uncertainty assessment.

\section{FIGURE B.5 HERE (TWO COLUMN WIDTH)}

Fig. B.5 shows the CDFs and histograms corresponding to the rectangle number 15 after the inversion using absolute constraints (left) and without using absolute constraints ${ }^{2}$ (right). The rectangle number 15 is situated in the neighborhood of one of the absolute constraints, but not strictly contiguous, so it is a good can-

\footnotetext{
${ }^{2}$ All the other parameters in this inversion are the same as in the case of the previous experiment.
} 
didate to check the influence of this kind of constraints not only in the affected rectangles itself, but also in a small area around it. As it can be seen, in both cases the histogram presents only one maximum and a near symmetrical shape, but in the inversion with absolute constraints the estimated depth is closer to the true one that in the case of inversion without absolute constraints. So the use of absolute constraints has influence not only in the affected rectangles, but also in their neighborhood. Finally, the estimated regional trend has parameters of value $A_{0}=-98.675 \mathrm{mGal}$, and $A_{1}=1.2117 \cdot 10^{-3} \mathrm{mGal} \mathrm{m}^{-1}$, presenting their corresponding histograms (not shown here) only one mode.

Figs. B.3, B.4, and B.5 show, together with the estimated model, the true model (green line). As it can be shown, there are differences between it and the best and median models. All these differences are a consequence of the well known characteristics of inverse problems, i. e., their inherent non-uniqueness in the case of potential field based methods, the presence of noise in observations (Fernández-Martínez et al., 2014a,b), the always finite number of observations, the idealization of the model, which is in all cases a simplification of the reality, etc. All these sources of uncertainty make the task of the inverse problems not only to find the best model, considered as the one that adjusts the observations with minimum misfit, but a task of determination of a collection of models that are compatible at a certain level of error with all the prior information (observations, previous models, particular information of a specific parameter, etc.) at a disposal (Scales and Snieder, 2000; Tarantola, 2006). 


\section{Real example}

An application of GRAvPSO2D package for the inversion of observed gravity data is provided in this section. For more reliability with our previous works describing the theoretical aspects of the inversion scheme (Pallero et al., 2015; Fernández-Martínez et al., 2017) we provide here the original data corresponding to the gravity profile already discussed in these papers. In addition, with the aim at giving more replicable examples for users we have also extended this dataset with 3 other available gravity profiles also acquired during the same survey.

This dataset, acquired from a gravity survey carried out in the Atacama Desert (north Chile) by Gabalda et al. (2005), with the purpose of the basement relief of a sedimentary basin estimation, where irregular sediment thickness was suspected (presence of paleo-valleys). This region of central Andes (see Fig. B.6 for a general overview) is characterized by these continental sediments, known as the Atacama Gravels formation, derived from the Andes mountains' erosion, and deposited in a central depression formed during the built up of the Andean system in response to the subduction of the oceanic Nazca plate beneath the South American continent (Mortimer, 1973; Riquelme, 2003). These sediments deposited on the western flank of the Andean system in El Salado valley are composed of low density materials (fluvial gravels, sand and clays intercalated with ignimbrite layers (Cornejo et al., 1993)). As described in Nalpas et al. (2008), the Atacama Gravels preserved along of the Río Salado catchment represent the infill of a drainage system of paleo-valleys converging to a canyon outlet open towards the Pacific Ocean (see Fig. B.7, dash line with arrow), indicating exoreic conditions just before sedimentation. The preservation of the Atacama Gravels was related to a fall of fluvial transport capacity (limiting the mass transfer to the ocean and initiat- 
ing the sedimentation) consecutive to a progressive climatic shift towards aridity during the Miocene. Field observations suggest that the thickness of the Atacama Gravels may reach around $150 \mathrm{~m}$ to $200 \mathrm{~m}$ in the Central Depression, and up to $500 \mathrm{~m}$ in the "Pampa del Inca" paleovalley north of Potrerillos in the Domeyko Cordillera (Nalpas et al., 2008).

\section{FIGURE B.6 HERE (TWO COLUMN WIDTH)}

The density contrast sediments-basement has been estimated at around $\Delta \rho=$ $-800 \mathrm{~kg} \mathrm{~m}^{-3}$ (Gabalda et al., 2005). This high density contrast and the well preserved nature of these basins, due to the arid climatic conditions in this region, make the Atacama Gravels formation a suitable candidate for basement relief estimation via the gravity inverse problem. Moreover, two observable contacts along the El Salado valley between the dense substratum and the low density sedimentary filling (Figs. B.6 and B.7, red stars) provide valuable information for the gravity data inversion interpretation. Details on the gravity and GPS data acquisition and processing performed according to the state-of-the-art for precise gravity surveys can be found in Gabalda et al. (2003, 2005).

\section{FIGURE B.7 HERE (TWO COLUMN WIDTH)}

The dataset is composed of four gravity profiles acquired in uneven topography area with elevations ranges between $800 \mathrm{~m}$ to $2400 \mathrm{~m}$ (see location of the 4 profiles on Figs. B.6, and B.7). Three of them (P1, P2, and P3) have an orientation W-E and an average altitude between $1200 \mathrm{~m}$ and $1500 \mathrm{~m}$, while the fourth one (P4) shows an orientation mainly NW-SE and an average altitude of about $2100 \mathrm{~m}$ (in any case, all profiles present an ascending topography eastward). The number of observed gravity measurements and the lengths for each profile are respectively 52 points and $25 \mathrm{~km}$ for $\mathrm{P} 1,53$ points and $31 \mathrm{~km}$ for $\mathrm{P} 2,51$ points 
and $18 \mathrm{~km}$ for $\mathrm{P} 3$, and 32 points and $14 \mathrm{~km}$ for $\mathrm{P} 4$. The uncertainties of gravity and height data are estimated to be better than $20 \mu \mathrm{Gal}$ and $5 \mathrm{~cm}$ respectively. The interpreted final gravity values (complete Bouguer anomalies) include terrain corrections computed using a $90 \mathrm{~m}$ resolution topographic model.

In order to apply GravPSO2D to the observed profiles, we have used in all cases the CP-PSO family member, a swarm of 200 models with 200 iterations, and 3 repetitions were combined, which means that a total of 120000 generated models for each profile inversion. The $L_{2}$ norm was used for the cost function evaluation, and two passes of a 3-element filter window with coefficients equal to 1 was applied. In all cases, a fixed density contrast sediments-basement of $\Delta \rho=-800 \mathrm{~kg} \mathrm{~m}^{-3}$ was employed accordingly to previous estimations (Gabalda et al., 2005). The subsoil for each profile has been discretized into vertical rectangles of width corresponding to the mean separation of the observed gravity measurements. We thus obtain, 52 rectangles of width equal to $490 \mathrm{~m}$ for P1, 53 rectangles of width equal to $550 \mathrm{~m}$ for $\mathrm{P} 2,52$ rectangles of width $360 \mathrm{~m}$ for P3 and 33 rectangles of width $420 \mathrm{~m}$ for $\mathrm{P} 4$. A first regional trend approximation is automatically subtracted from the observed Bouguer anomaly profile with the objective of isolate the residual gravity anomaly. The final regional trend (first order polynomial was chosen) is automatically estimated during the inversion process for removing the long wavelength gravity signal produced by the regional gravity (here mostly related with the deep crustal root of the Andes). In our case, the residual signal is thus supposed to be generated by the sedimentary filling of the Atacama Gravels formation in a local pre-existing morphological basin. The results of the inversion process are discussed hereafter.

FIGURE B.8 HERE (TWO COLUMN WIDTH) 
Fig. B.8 shows the median estimated models for P1 (left), and P2 (right), together with the 5\% relative error equivalent region. In the case of P1, the profile shows two sub-basins, separated at approximately a length of $15 \mathrm{~km}$ along the profile by an outcropped basement observable in the field. The westwards sub-basin presents a maximum depth of $100 \mathrm{~m}$ with limits for the $5 \%$ equivalent region between $92 \mathrm{~m}$, and $108 \mathrm{~m}$. The eastwards sub-basin shows a maximum depth of $93 \mathrm{~m}$ with limits for the 5\% equivalent region between $86 \mathrm{~m}$, and $100 \mathrm{~m}$. Fig. B.11 (left and center) shows the cumulative distribution functions and the corresponding histograms for the two described rectangles corresponding to the maximum thickness. In P2 a deeper filling is observed in the first half of the profile, where the maximum depth reaches $227 \mathrm{~m}$, with limits for the 5\% equivalent region between $196 \mathrm{~m}$ and $256 \mathrm{~m}$. Fig. B.11 (right) shows the cumulative distribution function and the corresponding histogram for this deepest point. As it can be seen, although the depth amplitude for the 5\% equivalent region in this case is apparently wide (around $60 \mathrm{~m}$ ), the histogram shows there is a clear maximum between depths $220 \mathrm{~m}$ and $230 \mathrm{~m}$, so this region contains the maximum probability for the rectangle's depth.

\section{FIGURE B.9 HERE (TWO COLUMN WIDTH)}

Fig. B.9 shows the median estimated models for P3 (left), and P4 (right), together with the 5\% relative error equivalent region. In the case of P3, the profile shows an irregular basin bottom topography, with a shallow region around a distance of $7 \mathrm{~km}$ from the initial point that divides the profile in two sub-basins. The westwards sub-basin presents a maximum depth of about $109 \mathrm{~m}$ with limits for the $5 \%$ equivalent region between $96 \mathrm{~m}$, and $122 \mathrm{~m}$. The eastwards sub-basin shows a maximum depth of $110 \mathrm{~m}$ with limits for the 5\% equivalent region between 
$100 \mathrm{~m}$, and $121 \mathrm{~m}$. Fig. B.12 (left and center) shows the cumulative distribution functions and the corresponding histograms for the two described rectangles. In P4 the deepest region corresponds roughly to the center of the profile, where the maximum depth reaches around $322 \mathrm{~m}$, being the deepest point in the four profiles. The limits for the $5 \%$ equivalent region are between $300 \mathrm{~m}$, and $344 \mathrm{~m}$. Fig. B.12 (right) shows the cumulative distribution function and the corresponding histogram for the rectangle. About the estimated regional trend, all profiles present a slope of value $\sim-3.26 \mathrm{mGal} \mathrm{km}^{-1}$ (the adjusted values corresponding to the median models are $-3.35 \mathrm{mGal} \mathrm{km}^{-1},-3.23 \mathrm{mGal} \mathrm{km}^{-1},-3.26 \mathrm{mGal} \mathrm{km}^{-1}$, and $-3.23 \mathrm{mGal} \mathrm{km}^{-1}$ for profiles P1, P2, P3, and P4 respectively). Fig. B.13 shows the original and residual anomaly, as well as the adjusted trend for the P1 (left), and P2 (right) profiles, while Fig. B.14 represents the same data for the P3 (left), and P4 (right) profiles.

In addition to the geological constraints given on the termination of the sedimentary filling (outcropping basement) along the surveyed gravity profiles, we also have direct field observations of the actual thickness of the Atacama Gravels near the profiles P2 and P4 revealed by the erosion of the Río Salado, which allows to see locally the altitude of the base of the gravels (see Figs. B.6, and B.7, red stars). These deposits correspond to a sedimentary layer with a variable thickness, moderate in the central depression (100 $\mathrm{m}$ to $200 \mathrm{~m}$ ) and more important upstream for the paleovalleys, which reach the Cordillera of Domeyco (going up to $500 \mathrm{~m}$ ), like the "Pampa del Inca" paleovalley, north of Potrerillos (Nalpas et al., 2008).

For the P4 profile the "Quebrada El Salado" completely intersects the Atacama Gravels NE of the profile, a little upstream of the paleovalley of the "Pampa del Inca", where the maximum thickness of the Graves of Atacama is about $360 \mathrm{~m}$ 
(base at $1820 \mathrm{~m}$, top at $2180 \mathrm{~m}$ ). This value in the field is entirely in agreement with the thickness deduced from the inversion of the P4 profile which is $322 \mathrm{~m}$ (see Figs. B.9, right, and B.12, right), about $40 \mathrm{~m}$ less which corresponds to the gradual decrease in the thickness of the Atacama Gravels on along the paleovalley towards the central depression.

For the P2 profile the "Quebrada El Salado" cuts the Atacama Gravels near the western end of the El Salvador runway, where the maximum observed thickness of the Graves of Atacama is about $70 \mathrm{~m}$ (base at $1425 \mathrm{~m}$, and top at $1495 \mathrm{~m}$ ). As the point is located on the southern edge of the paleovalley coming from El Salvador, it is expected to have a slightly smaller thickness compared to the value of the profile, around $80 \mathrm{~m}$, which is more in the axis of this paleovalley.

\section{Conclusions}

In this paper GRAvPSO2D, a Matlab software for 2D gravity inversion in sedimentary basins using the Particle Swarm Optimization algorithm has been presented. This software represents the first effort to provide the scientific community with a tool based on the PSO for this particular problem. GravPSO2D is freely available and includes an exhaustive reference manual where all the details related to the input data, file formats, and output results are exposed and analyzed.

It is of particular importance for results interpretation the analysis of the posterior probability distributions of the parameters, an important task that can be accomplished with the help of the powerful and smart ability of the PSO algorithm for sampling the parameters space. We showed its application to sedimentary basin relief estimation in synthetic and real cases.

The real test case presented in this paper contains a dataset of various profiles 
corresponding to different basin geometries and depths. This dataset acquired in a context of uneven topography and of significant regional gravity anomaly also represent a standard gravity dataset that will enable the user to better handle the inversion and the parameterization taking into account the actual terrain topography and the regional trend. It can be concluded that GravPSO2D is a powerful software to invert and assess the uncertainty of the solution in this kind of problems via a whole family of PSO optimizers.

\section{Computer code availability}

The source code of GravPSO2D will be available free of charge in the BGI's webpage (http://bgi .obs-mip.fr/), and in https://github.com/jgpallero/ grav-pso-2d.

\section{Declaration of competing interest}

The authors declare that they have no known competing financial interests nor personal relationships that could have appeared to influence the work reported in this paper.

\section{Acknowledgments}

JLGP acknowledges the support of the GET (Université de Toulouse, CNRS, IRD, CNES), the Bureau Gravimétrique International (BGI), and CNES, that allowed him to develop part of this research in Toulouse during two research stays in 2018 and 2019 (work supported by CNES, CNRS and IRD). He also acknowledges the support of the Universidad Politécnica de Madrid through a Programa Propio de Movilidad grant in 2018. 
Appendix A. Gravity attraction due to a constant density rectangle over an exterior point

Let a rectangle of density $\rho$, defined by the coordinates (see Fig. B.10) $x$ minimum $x_{m}, x$ maximum $x_{M}, z$ of top side $z_{t}$, and $z$ of bottom side $z_{b}$. The gravitational attraction generated by this polygon at an arbitrary point $P(x, y)$ is (Barbosa and Silva, 1994; Telford et al., 1976)

$$
\begin{aligned}
F & =F\left(x, z, x_{m}, x_{M}, z_{t}, z_{b}, \rho\right) \\
& =G \rho\left[A \ln \frac{A^{2}+D^{2}}{A^{2}+C^{2}}-B \ln \frac{B^{2}+D^{2}}{B^{2}+C^{2}}\right. \\
& -2 C\left(\arctan \frac{A}{C}-\arctan \frac{B}{C}\right) \\
& \left.+2 D\left(\arctan \frac{A}{D}-\arctan \frac{B}{D}\right)\right],
\end{aligned}
$$

where $A=x-x_{m}, B=x-x_{M}, C=z-z_{t}, D=z-z_{b}$, and $G$ is the Newton's constant.

FIGURE B.10 HERE (ONE COLUMN WIDTH)

\section{Appendix B. Additional figures}

In this appendix some auxiliary figures referred in section 7 are shown.

FIGURE B.11 HERE (TWO COLUMN WIDTH)

FIGURE B.12 HERE (TWO COLUMN WIDTH)

FIGURE B.13 HERE (TWO COLUMN WIDTH)

FIGURE B.14 HERE (TWO COLUMN WIDTH) 


\section{References}

Al-Chalabi, M., 1971. Some studies relating to non uniqueness in gravity and magnetic inverse problems. Geophysics 36, 835-855. doi:10.1190/1. 1440219.

Barbosa, V.C.F., Silva, J.B.C., 1994. Generalized compact gravity inversion. Geophysics 95, 57-68. doi:10.1190/1.1443534.

Barbosa, V.C.F., Silva, J.B.C., Medeiros, W.E., 1997. Gravity inversion of basement relief using approximate equality constraints on depths. Geophysics 62, 1745-1757. doi:10.1190/1.1444275.

Barbosa, V.C.F., Silva, J.B.C., Medeiros, W.E., 1999. Gravity inversion of a discontinuous relief stabilized by weighted smoothness constraints on depth. Geophysics 64, 1429-1437. doi:10.1190/1.1444647.

Blakely, R.J., 1995. Potential Theory in Gravity and Magnetic Applications. Cambridge University Press.

Boschetti, F., Dentith, M., List, R., 1997. Inversion of potential field data by genetic algorithms. Geophysical Prospecting 45, 461-478. doi:10.1046/j . $1365-2478.1997 .3430267 . x$.

Bott, M.H.P., 1960. The use of rapid digital computing methods for direct gravity interpretation of sedimentary basins. Geophysical Journal of the Royal Astronomical Society 3,63-67. doi:10.1111/j.1365-246X .1960 . tb00065.x.

Brocher, T.M., 2005. A Regional View of Urban Sedimentary Basins in Northern California Based on Oil Industry Compressional-Wave Velocity and Den- 
sity Logs. Bulletin of the Seismological Society of America 95, 2093-2114. doi:10 . 1785/0120050025.

Chakravarthi, V., Sundararajan, N., 2007. 3D gravity inversion of basement reliefA depth-dependent density approach. Geophysics 72, 123-132. doi:10.1190/ 1.2431634 .

Chen, Z., Zhang, X.M.S., 2015. 3D gravity interface inversion constrained by a few points and its GPU acceleration. Computers and Geosciences 84, 20-28. doi:10.1016/j.cageo.2015.08.002.

Cornejo, P., Mpodozis, C., Ramírez, C.F., Tomlinson, A.J., 1993. Estudio Geológico de la región de El Salvador y Potrerillos. Informe Registrado IR 93-1. Servicio Nacional de Geología y Minería. Santiago de Chile.

Dobrin, M.B., 1960. Introduction to geophysical prospecting. 2 ed., McGrawHill.

Ekinci, Y.L., Balkaya, Ç., Göktürkler, G., Özyalın, Ş., 2020. Gravity data inversion for the basement relief delineation through global optimization: a case study from the Aegean Graben System, western Anatolia, Turkey. Geophysical Journal International doi:10.1093/gji/ggaa492.

Essa, K.S., Elhussein, M., 2018. PSO (Particle Swarm Optimization) for Interpretation of Magnetic Anomalies Caused by Simple Geometrical Structures. Pure and Applied Geophysics 175, 3539-3553. doi:10.1007/ s00024-018-1867-0.

Fernández-Álvarez, J.P., Fernández-Martínez, J.L., García-Gonzalo, E., Menéndez-Pérez, C.O., 2006. Application of the particle swarm optimization 
algorithm to the solution and appraisal of the vertical electrical sounding inverse problem, in: 10th Annual Conference of the International Association of Mathematical Geology (IAMG '06), Liège, Belgium.

Fernández-Martínez, J.L., Fernández-Muñiz, Z., Pallero, J.L.G., Bonvalot, S., 2017. Linear geophysical inversion via the discrete cosine pseudo-inverse: application to potential fields. Geophysical Prospecting 65, 94-111. doi:10. $1111 / 1365-2478.12548$.

Fernández-Martínez, J.L., Fernández-Muñiz, Z., Pallero, J.L.G., PedrueloGonzález, L.M., 2013. From Bayes to Tarantola: New insights to understand uncertainty in inverse problems. Journal of Applied Geophysics 98, 62-72. doi:10.1016/j.jappgeo.2013.07.005.

Fernández-Martínez, J.L., García-Gonzalo, E., 2009. The PSO family: deduction, stochastic analysis and comparison. Swarm Intelligence 3, 245-273. doi:10. $1007 / \mathrm{s} 11721-009-0034-8$.

Fernández-Martínez, J.L., García-Gonzalo, E., 2012. Stochastic Stability and Numerical Analysis of Two Novel Algorithms of PSO Family: PP-PSO and RR-PSO. International Journal on Artificial Intelligence Tools 21, 20 pages. doi:10.1142/S0218213012400118.

Fernández-Martínez, J.L., García-Gonzalo, E., Fernández-Álvarez, J.P., 2008. Theoretical analysis of particle swarm trajectories through a mechanical analogy. International Journal of Computational Intelligence Research 4, 93-104. doi:10.5019/j.ijcir.2008.129. 
Fernández-Martínez, J.L., García-Gonzalo, E., Fernández Álvarez, J.P., Kuzma, H.A., Menéndez Pérez, C.O., 2010a. PSO: A powerful algorithm to solve geophysical inverse problems. Application to a 1D-DC resistivity case. Journal of Applied Geophysics 71, 13-25. doi:10.1016/j . jappgeo.2010.02.001.

Fernández-Martínez, J.L., García-Gonzalo, E., Naudet, V., 2010b. Particle swarm optimization applied to solving and appraising the streaming-potential inverse problem. Geophysics 75, WA3-WA15. doi:10.1190/1.3460842.

Fernández-Martínez, J.L., Pallero, J.L.G., Fernández-Muñiz, Z., PedrueloGonzález, L.M., 2014a. The effect of noise and Tikhonov's regularization in inverse problems. Part I: The linear case. Journal of Applied Geophysics 108, 176-185. doi:10.1016/j.jappgeo.2014.05.006.

Fernández-Martínez, J.L., Pallero, J.L.G., Fernández-Muñiz, Z., PedrueloGonzález, L.M., 2014b. The effect of noise and Tikhonov's regularization in inverse problems. Part II: The nonlinear case. Journal of Applied Geophysics 108, 186-193. doi:10.1016/j.jappgeo.2014.05.005.

Fernández-Muñiz, Z., Pallero, J.L.G., Fernández-Martínez, J.L., 2020. Anomaly shape inversion via model reduction and PSO. Computers and Geosciences 140, 104492. doi:10.1016/j . cageo. 2020 . 104492.

Gabalda, G., Bonvalot, S., Hipkin, R., 2003. CG3TOOL: An interactive computer program for Scintrex CG-3M gravity data processing. Computers \& Geosciences 29, 155-171. doi:10.1016/S0098-3004(02)00114-0.

Gabalda, G., Nalpas, T., Bonvalot, S., 2005. The Base of the Atacama Gravels Formation $\left(26^{\circ} \mathrm{S}\right.$, Northern Chile): First results from gravity data, in: 6th 
International Symposium on Andean Geodynamics (ISAG 2005, Barcelona). Extended Abstracts, Paris, IRD. pp. 286-289.

García-Gonzalo, E., Fernández-Martínez, J.L., 2009. Design of a simple and powerful Particle Swarm optimizer, in: Vigo-Aguiar, J. (Ed.), Proceedings of the 2009 International Conference on Computational and Mathematical Methods in Science and Engineering (volume 4), Gijón, Spain, 30 June-3 July 2009. pp. 1280-1291. URL: http://cmmse.usal.es/cmmse2018/sites/default/ files/volumes/volumen4opt.pdf.

García-Gonzalo, E., Fernández-Martínez, J.L., Cernea, A., 2014. Four-Points Particle Swarm Optimization Algorithms. Journal of Multiple-Valued Logic and Soft Computing 22, 239-266.

Granser, H., 1987. Three-dimensional interpretation of gravity data from sedimentary basins using an exponential density-depth function. Geophysical Prospecting 35, 1030-1041. doi:10.1111/j.1365-2478.1987.tb00858.x.

Hinze, W.J., von Frese, R.R.B., Saad, A.H., 2013. Gravity and Magnetic Exploration. Principles, Practices and Applications. 1 ed., Cambridge University Press, Cambridge, UK.

Kennedy, J., Eberhart, R., 1995. Particle swarm optimization, in: IEEE International Conference on Neural Networks (vol. 4), Perth, WA, 27 November-1 December 1995. pp. 1942-1948. doi:10.1109/ICNN.1995.488968.

Ladino, O.F., Bassrei, A., 2016. A hybrid fast 3D inversion algorithm of gravity data for basement relief definition, in: SEG Technical Program Expanded Abstracts 2016. SEG International Exposition and 86th Annual Meet- 
ing, Dallas, USA, 16-21 October 2016. pp. 1521-1525. doi:10.1190/ segam2016-13840764. 1.

Li, L., Tan, J., Xie, Y., Tan, Y., Walda, J., Zhao, Z., Gajewski, D., 2019. Waveform-based microseismic location using stochastic optimization algorithms: A parameter tuning workflow. Computers and Geosciences 124, 115127. doi:10.1016/j. cageo.2019.01.002.

Litinsky, V.A., 1989. Concept of effective density: Key to gravity determination for sedimentary basins. Geophysics 54, 1474-1482. doi:10.1190/1.1442611.

Luu, K., Noble, M., Gesret, A., Belayouni, N., Roux, P.F., 2018. A parallel competitive Particle Swarm Optimization for non-linear first arrival traveltime tomography and uncertainty quantification. Computers and Geosciences 113, 81-93. doi:10.1016/j.cageo.2018.01.016.

Mortimer, C., 1973. The Cenozoic history of the southern Atacama Desert, Chile. Journal of the Geological Society 129, 505-526. doi:10.1144/gs jgs.129. 5. 0505.

Nalpas, T., Dabard, M.P., Ruffet, G., Vernon, A., Mpodozis, C., Loi, A., Hérail, G., 2008. Sedimentation and preservation of the Miocene Atacama Gravels in the Pedernales-Chañaral Area, Northern Chile: Climatic or tectonic control? Tectonophysics 459, 161-163. doi:10.1016/j . tecto. 2007.10.013.

Nettleton, L.L., 1976. Gravity and magnetics in oil prospecting. McGraw-Hill.

Pallero, J.L.G., Fernández-Martínez, J.L., Bonvalot, S., Fudym, O., 2015. Gravity inversion and uncertainty assessment of basement relief via Particle Swarm 
Optimization. Journal of Applied Geophysics 116, 180-191. doi:10.1016/j . jappgeo.2015.03.008.

Pallero, J.L.G., Fernández-Martínez, J.L., Bonvalot, S., Fudym, O., 2017. 3D gravity inversion and uncertainty assessment of basement relief via Particle Swarm Optimization. Journal of Applied Geophysics 139, 338-350. doi:10 . 1016/j.jappgeo.2017.02.004.

Pallero, J.L.G., Fernández-Muñiz, M.Z., Cernea, A., Álvarez-Machancoses, Ó., Pedruelo-González, L.M., Bonvalot, S., Fernández-Martínez, J.L., 2018. Particle Swarm Optimization and Uncertainty Assessment in Inverse Problems. Entropy 20. doi:10.3390/e20020096.

Parker, P.B., 1999. Genetic Algorithms and Their Use in Geophysical Problems. Ph.D. thesis. University of California at Berkeley. Ernest Orlando Lawrence Berkeley National Laboratory. Earth Sciences Division. URL: http://www . osti.gov/scitech/biblio/8770/, doi:10.2172/8770.

Parker, R.L., 1972. The Rapid Calculation of Potential Anomalies. Geophysical Journal of the Royal Astronomical Society 31, 447-455. doi:10.1111/j . 1365-246X.1973.tb06513.x.

Parker, R.L., 1994. Geophysical Inverse Theory. Princeton University Press.

Pham, L.T., Oksum, E., Do, T.D., 2018. GCH_gravinv: A MATLAB-based program for inverting gravity anomalies over sedimentary basins. Computers and Geosciences 120, 40-47. doi:10.1016/j.cageo.2018.07.009.

Pick, M., Pícha, J., Vyskočil, V., 1973. Theory of the Earth's Gravity Field. Elsevier. 
Rao, D.B., 1990. Analysis of gravity anomalies of sedimentary basins by an asymmetrical trapezoidal model with quadratic density function. Geophysics 55, 226-231. doi:10.1190/1.1442830.

Riquelme, R., 2003. Evolution géomorphologique néogène des Andes centrales du Désert d'Atacama (Chili): interactions tectonique-érosion-climat. Ph.D. thesis. Universidad de Chile, Université Toulouse III-Paul Sabatier.

Roshan, R., Singh, U.K., 2017. Inversion of residual gravity anomalies using tuned PSO. Geoscientific Instrumentation, Methods and Data Systems 6, 7179. doi:10.5194/gi-6-71-2017.

Sanyi, Y., Shangxu, W., Nan, T., 2009. Swarm intelligence optimization and its application in geophysical data inversion. Applied Geophysics 6, 166-174. doi:10.1007/s11770-009-0018-x.

Scales, J.A., Snieder, R., 2000. The Anatomy of Inverse Problems. Geophysics 65, 1708-1710. doi:10.1190/geo2000-0001.1.

Shaw, R., Srivastava, S., 2007. Particle swarm optimization: A new tool to invert geophysical data. Geophysics 72, F75-F83. doi:10.1190/1. 2432481.

Silva, J.B.C., Costa, D.C.L., Barbosa, V.C.F., 2006. Gravity inversion of basement relief and estimation of density contrast variation with depth. Geophysics 71, J51-J58. doi:10.1190/1. 2236383.

Silva, J.B.C., Teixeira, W.A., Barbosa, V.C.F., 2009. Gravity data as a tool for landfill study. Environmental Geology 57, 749-757. doi:10.1007/ s00254-008-1353-6. 
Singh, A., Biswas, A., 2016. Application of Global Particle Swarm Optimization for Inversion of Residual Gravity Anomalies Over Geological Bodies with Idealized Geometries. Natural Resources Research 25, 297-314. doi:10.1007/s11053-015-9285-9.

Singh, K.K., Singh, U.K., 2017. Application of particle swarm optimization for gravity inversion of 2.5-D sedimentary basins using variable density contrast. Geoscientific Instrumentation, Methods and Data Systems 6, 193-198. doi:10. 5194/gi-6-193-2017.

Skeels, D.C., 1947. Ambiguity in gravity interpretation. Geophysics 12, 43-56. doi:10.1190/1.1437295.

Tarantola, A., 2006. Popper, Bayes and the inverse problem. Nature Physics 2, 492-494. URL: http://www.ipgp.fr/ tarantola/, doi:10.1038/ nphys 375.

Telford, W.M., Geldart, L.P., Sheriff, R.E., Keys, D.A., 1976. Applied Geophysics. Cambridge University Press.

Toushmalani, R., 2013a. Comparison result of inversion of gravity data of a fault by particle swarm optimization and Levenberg-Marquardt methods. SpringerPlus 2, 462. doi:10.1186/2193-1801-2-462.

Toushmalani, R., 2013b. Gravity inversion of a fault by Particle Swarm Optimization (PSO). SpringerPlus 2, 315. doi:10.1186/2193-1801-2-315.

Zhdanov, M.S., 2015. Inverse Theory and Applications in Geophysics. 2 ed., Elsevier. 


\section{LIST OF CAPTIONS}

Figure B.1: Two-dimensional basin model as an accretion of rectangles.

Figure B.2: Piecewise example model for vertical density contrast variation.

Figure B.3: Best model (left), and median model (right) obtained in the inversion of the reduced synthetic model using absolute constraints.

Figure B.4: Cumulative distribution function (top) and histogram (bottom) for the rectangle number 22 in the inversion of the reduced synthetic model using absolute constraints.

Figure B.5: Cumulative distribution functions and histograms for the rectangle number 15 in the inversion of the reduced synthetic model using absolute constraints (left), and without absolute constraints (right).

Figure B.6: Topography of the El Salado valley, observed gravity profiles P1 to $\mathrm{P} 4$, and location of the two points (red stars) of known sediments thickness.

Figure B.7: Geological background of the El Salado valley and observed gravity profiles $\mathrm{P} 1$ to $\mathrm{P} 4$.

Figure B.8: Median models for P1 (left), and P2 (right). Red points were not used in the cost function evaluation as they are situated in the outcropped basement.

Figure B.9: Median models for P3 (left), and P4 (right). Red points were not used in the cost function evaluation as they are situated in the outcropped basement.

Figure B.10: Rectangle of constant density and an exterior point to it.

Figure B.11: Cumulative distribution functions and histograms corresponding to the deepest points of the westwards (left) and eastwards (center) in the estimated median model for the P1 profile, and the deepest point in the estimated median 
model for the $\mathrm{P} 2$ profile (right).

Figure B.12: Cumulative distribution functions and histograms corresponding to the deepest points of the westwards (left) and eastwards (center) in the estimated median model for the $\mathrm{P} 3$ profile, and the deepest point in the estimated median model for the $\mathrm{P} 4$ profile (right).

Figure B.13: Gravity anomaly corresponding to the median models for the P1 (left), and P2 (right) profiles. Red points were not used in the cost function evaluation as they are situated in the outcropped basement.

Figure B.14: Gravity anomaly corresponding to the median models for the P3 (left), and P4 (right) profiles. Red points were not used in the cost function evaluation as they are situated in the outcropped basement.

\section{LIST OF FIGURES}

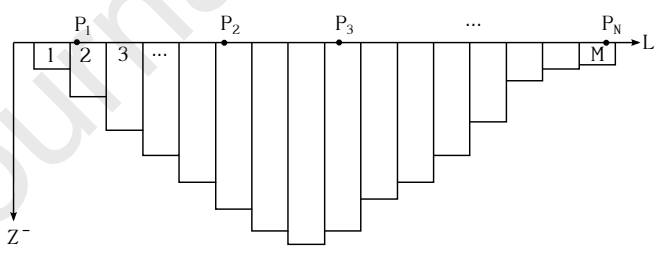

Figure B.1: 


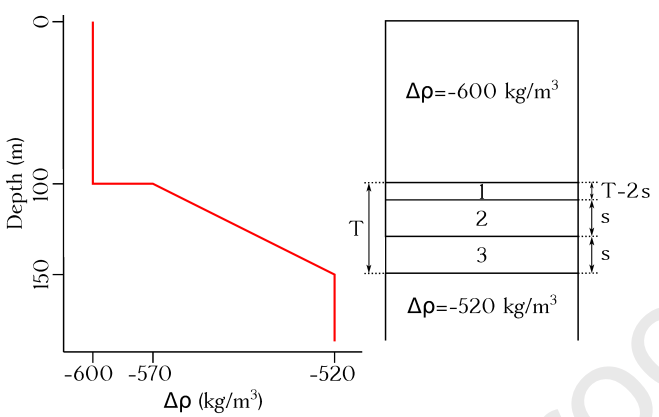

Figure B.2:
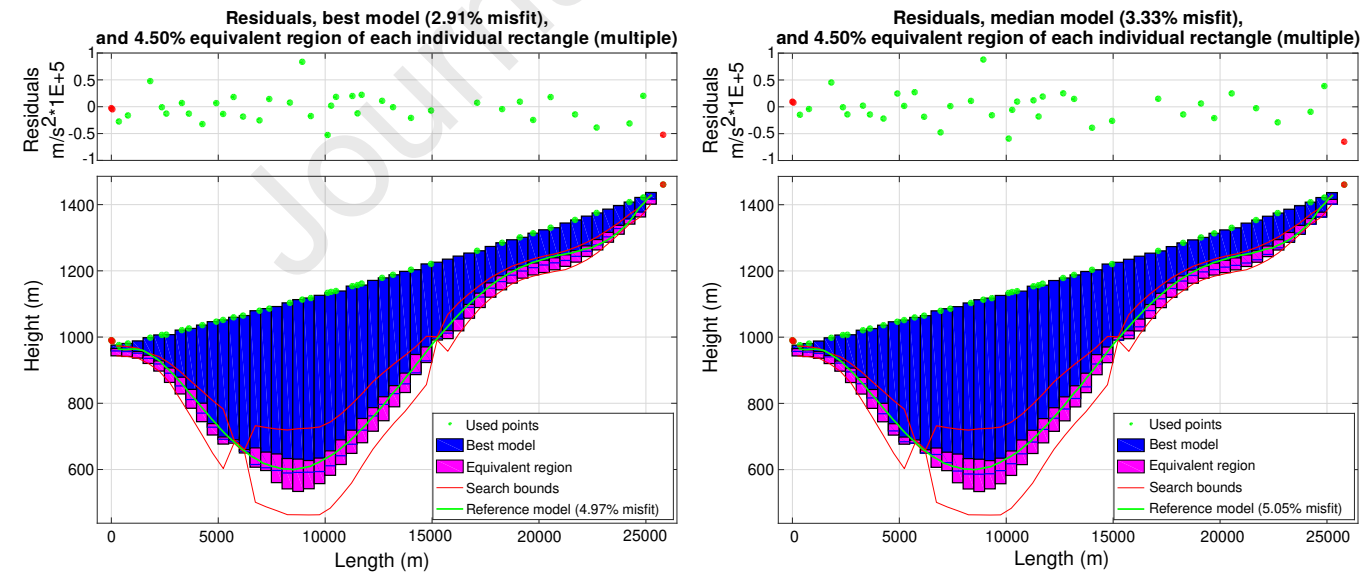

Figure B.3: 

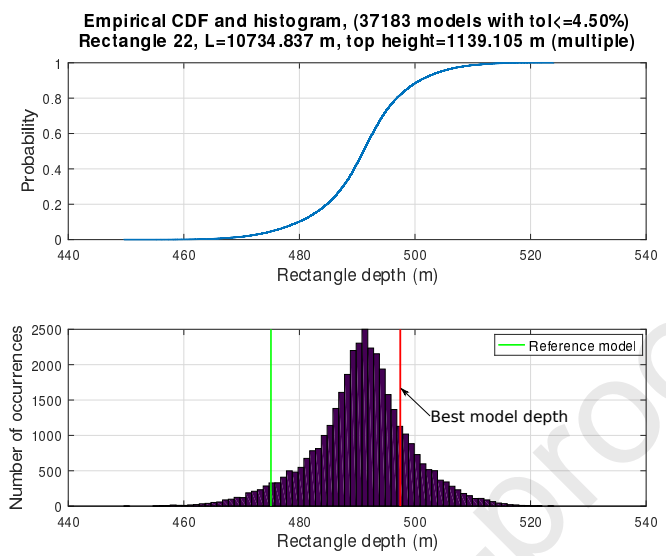

Figure B.4:
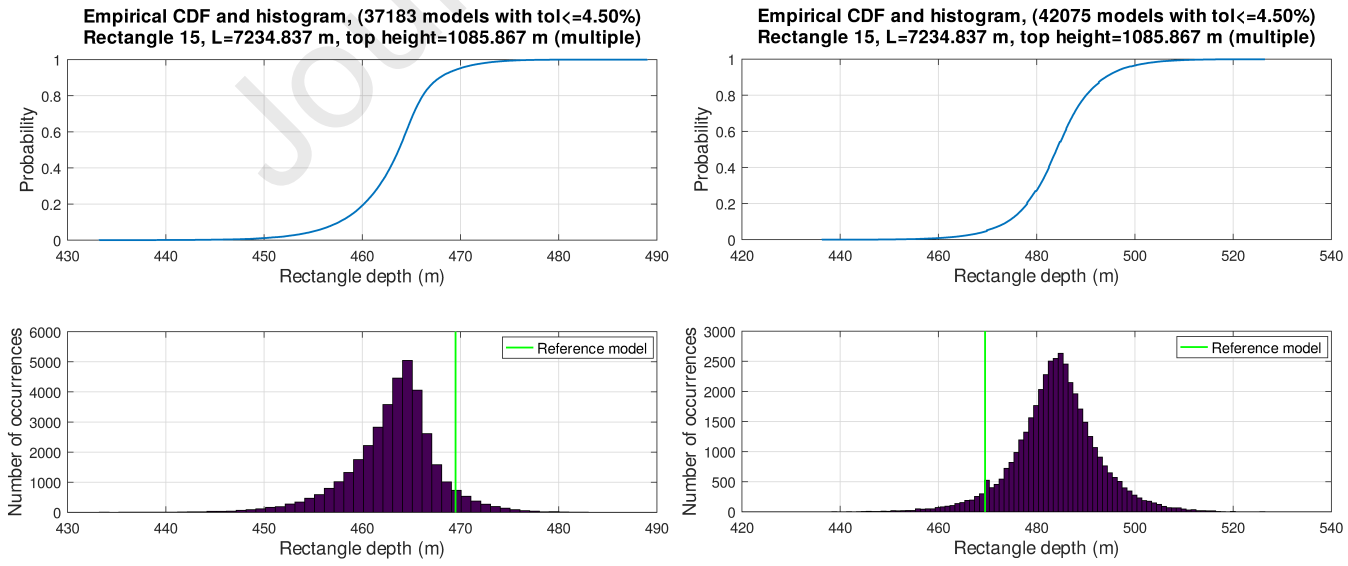

Figure B.5: 


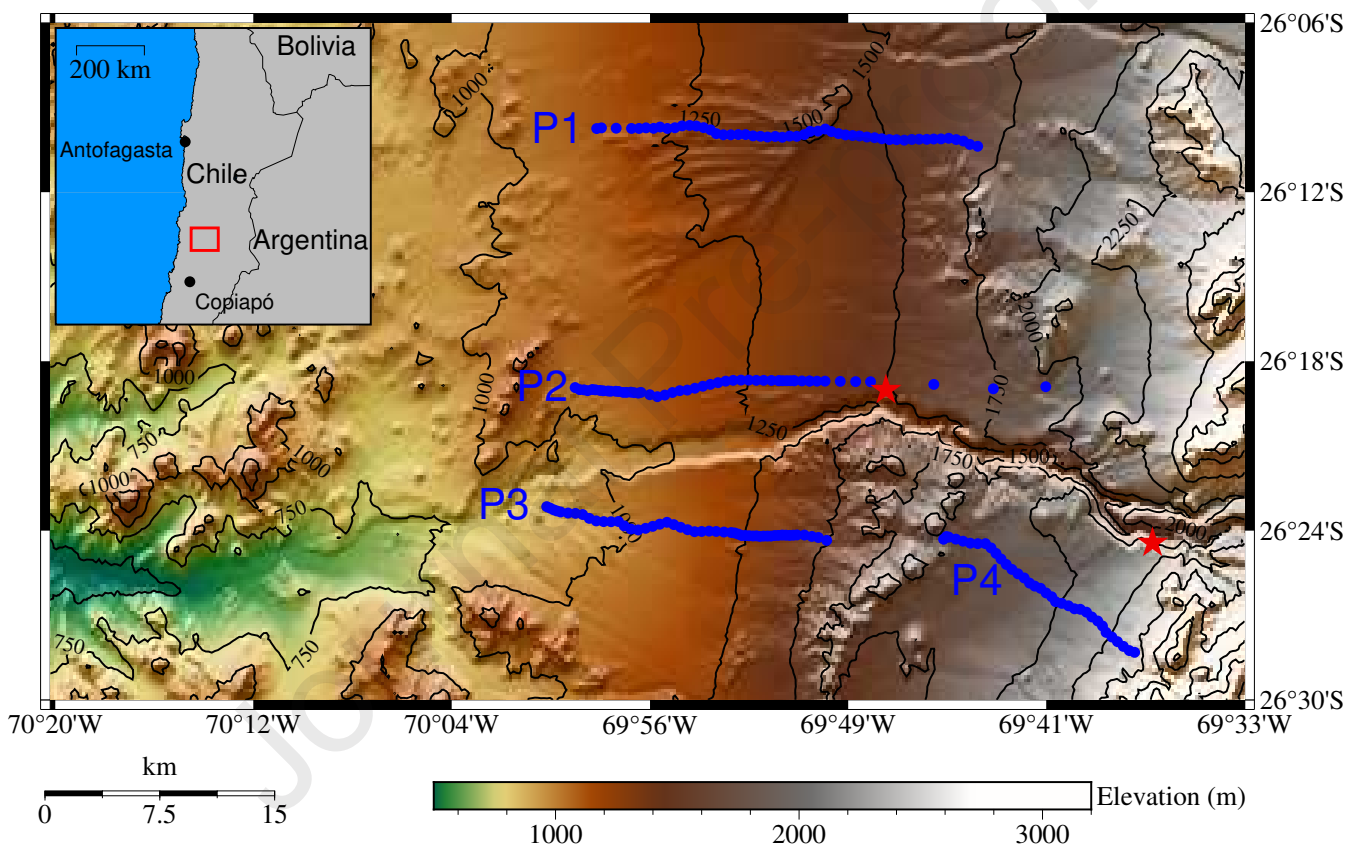

Figure B.6: 


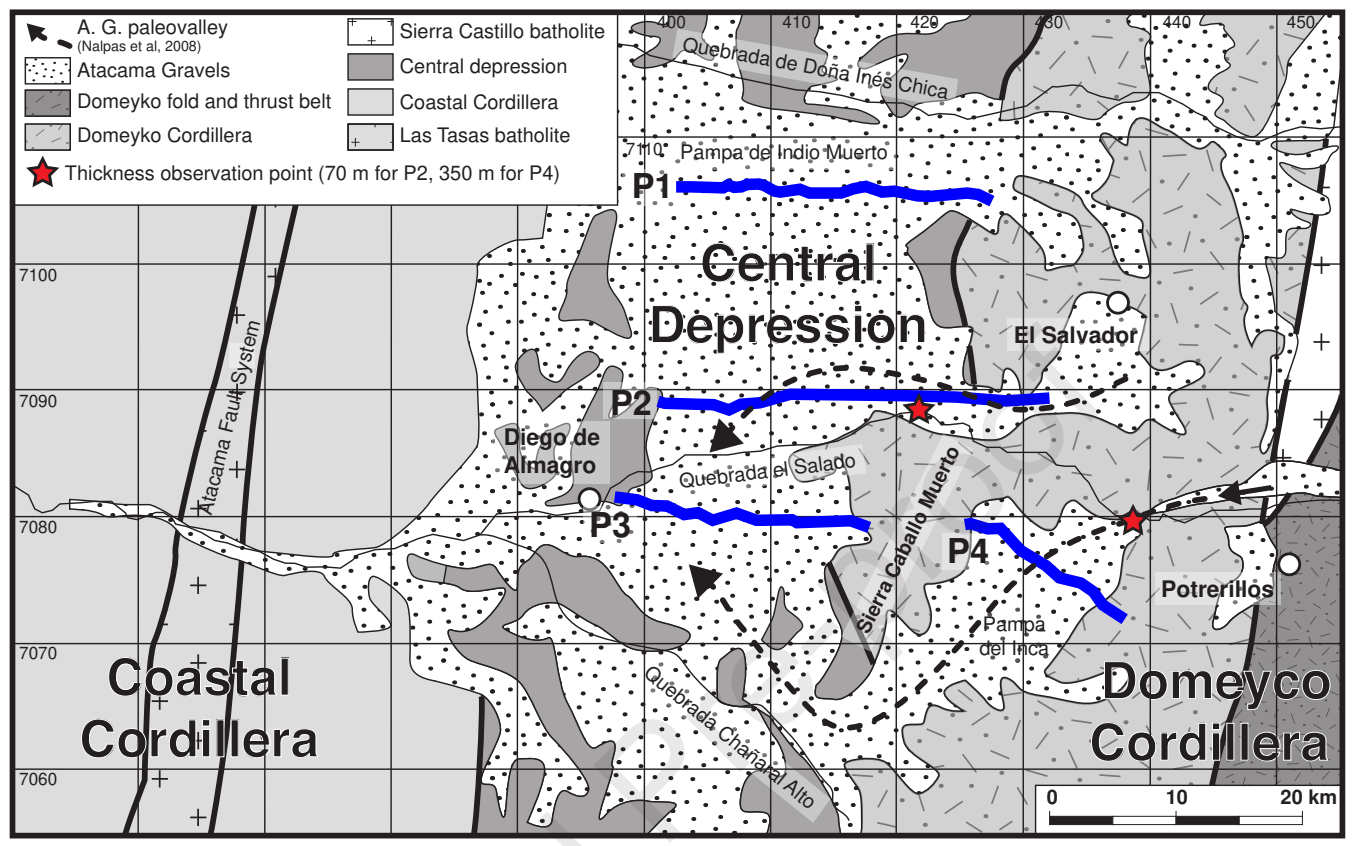

Figure B.7:
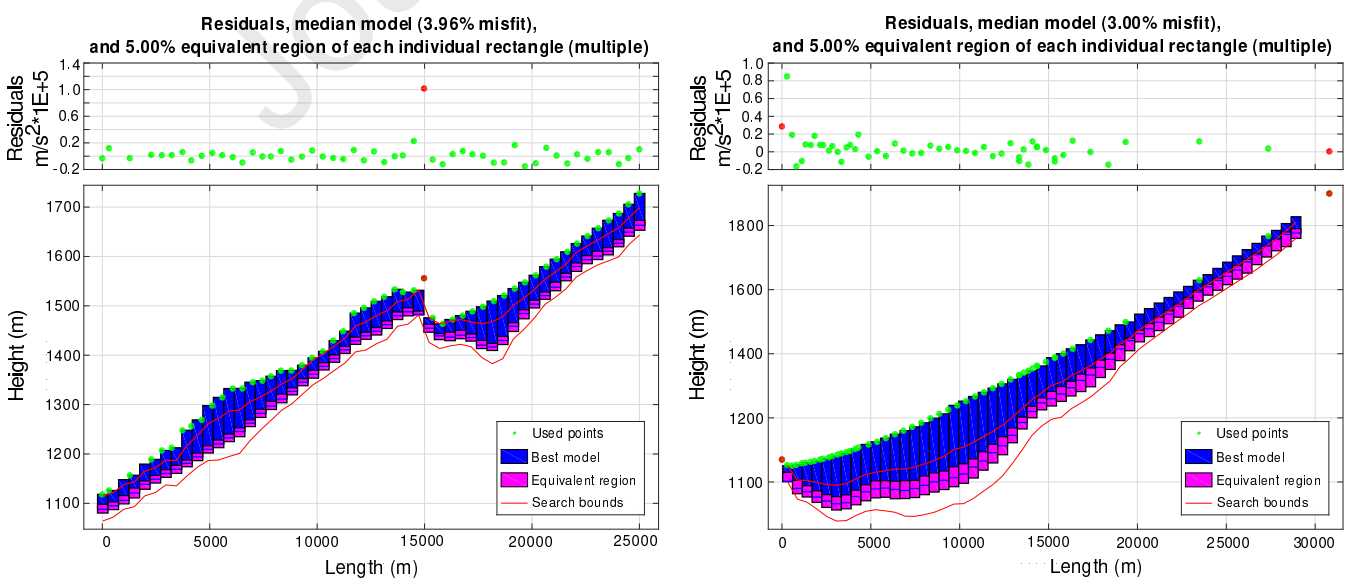

Figure B.8: 

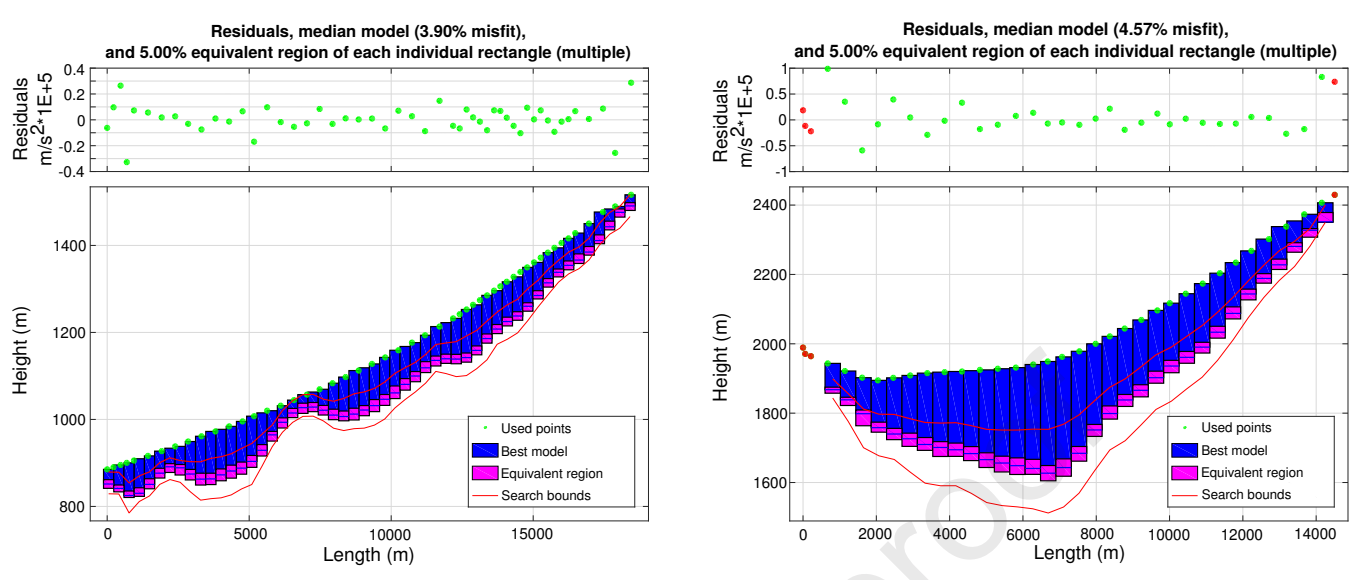

Figure B.9:

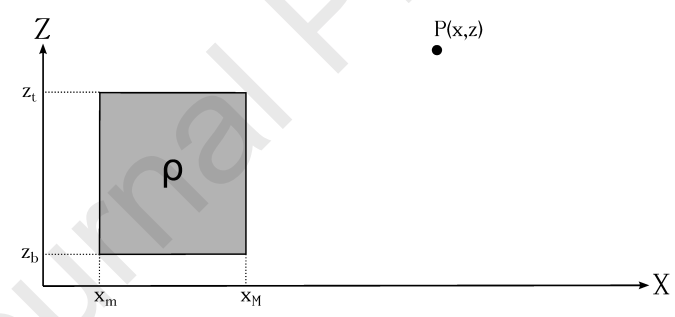

Figure B.10:
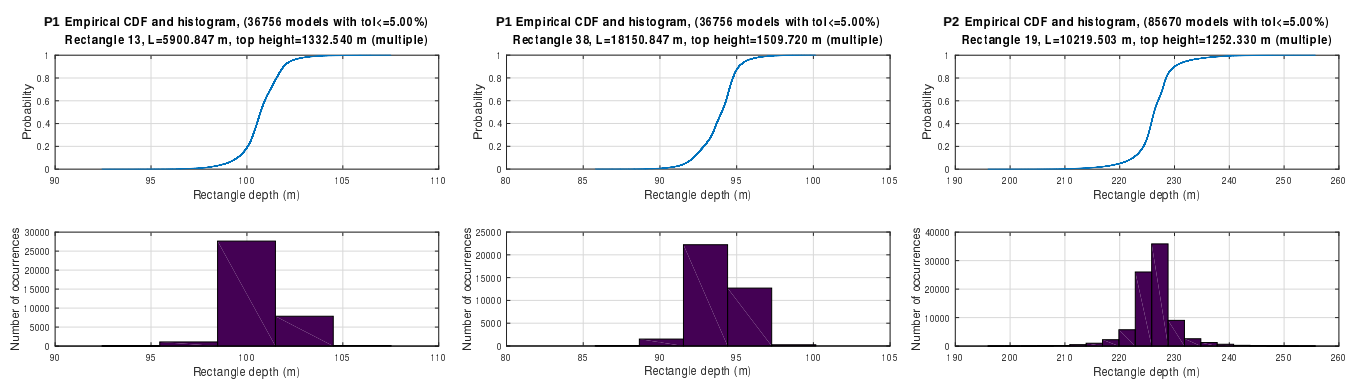

Figure B.11: 

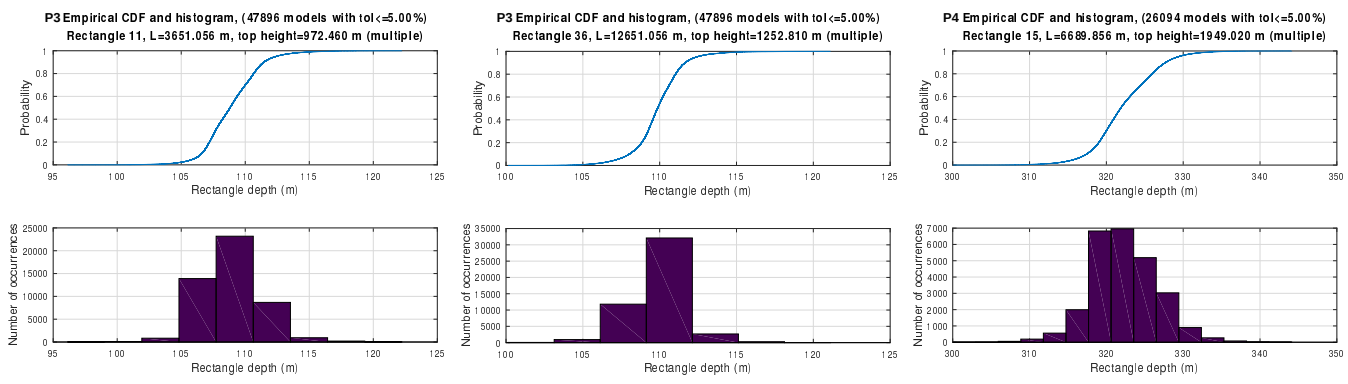

Figure B.12:
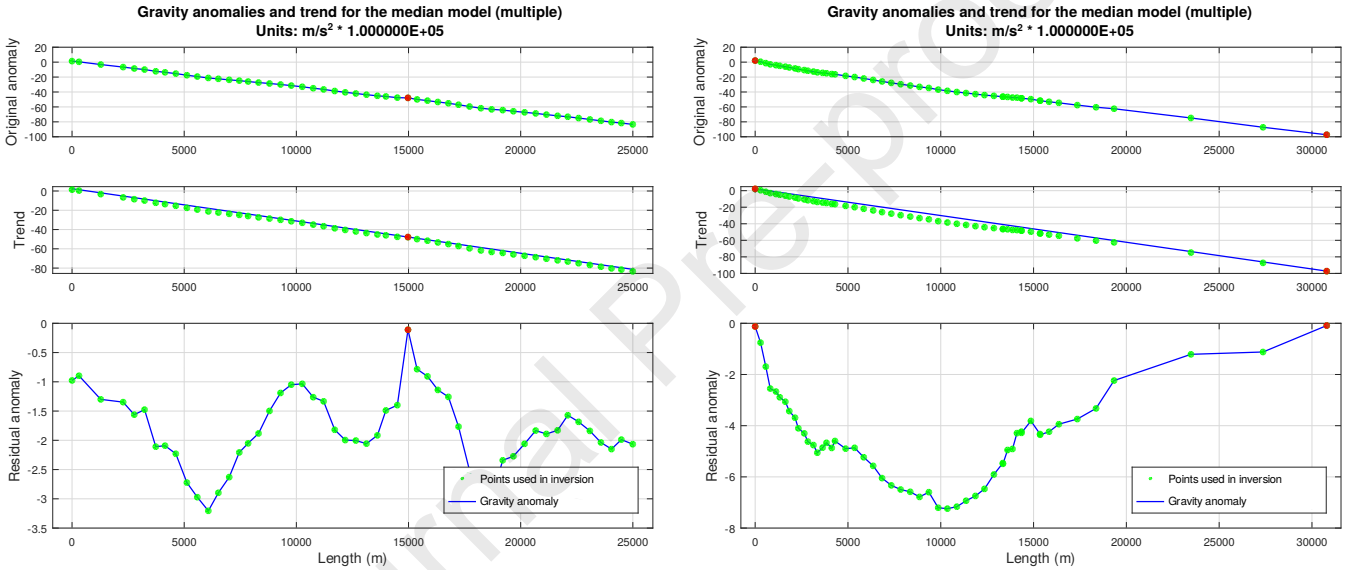

Figure B.13:
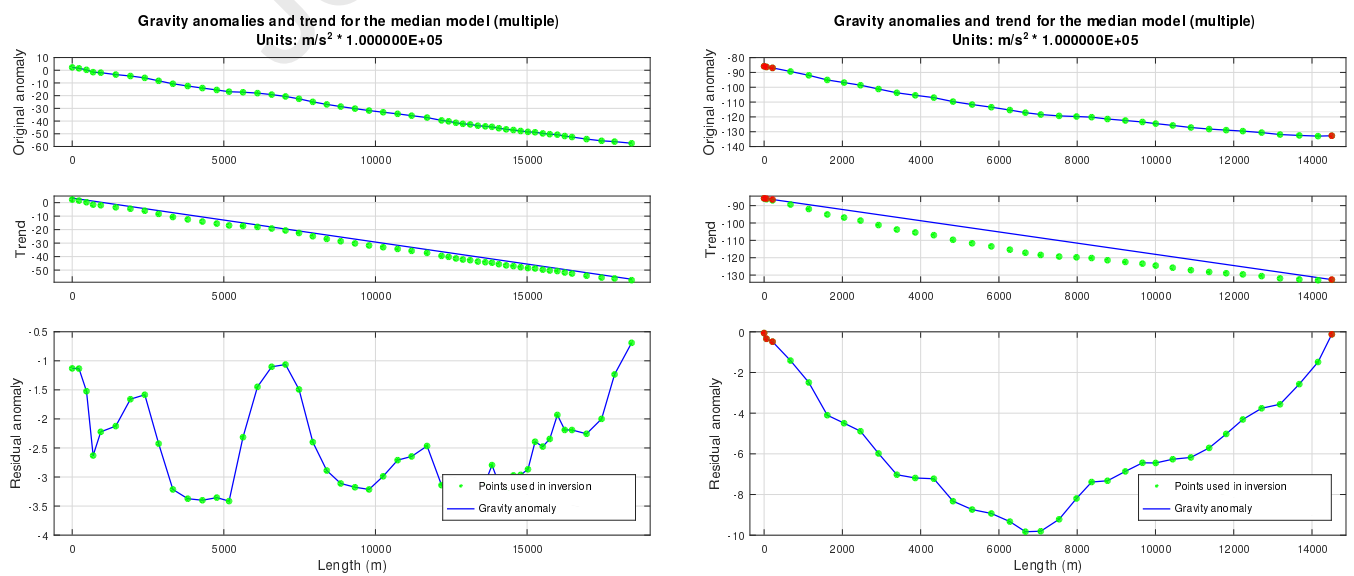

Figure B.14: 